\title{
Effect of Glucocorticoid Hormones on Growth of Human Fibroblast Cells and Interferon Production in a Microcarrier Culture System
}

\author{
Emiko Sano, Masahiko Iizuka and Sigeyasu Kobayashi* \\ Basic Research Laboratories, Toray Industries Inc., 1-111 Tebiro, Kamakura \\ 248, Japan
}

\begin{abstract}
Glucocorticoid hormones promoted the growth of fibroblast cells derived from human neonatal foreskins and prolonged their life span in a microcarrier culture system that used Eagle's minimum essential medium (MEM) supplemented with fetal calf serum (FCS). But, these hormones suppressed cell growth in conventional monolayer cultures.

Precolostrum newborn calf serum (PNCS) was the only species that supported the serial propagation of fibroblast cells on microcarriers, possibly because of its high content of hydrocortisone (HC).

Fibroblast cells grown on microcarriers in the presence of glucocorticoid hormones maintained their ability to produce interferon (IFN)- $\beta$ in a superinduction method with poly I : poly $\mathrm{C}$ and antimetabolites. These cells had more than $93 \%$ diploidy and no chromosomal aberration or translocation.

Use of PNCS for the cultivation of human fibroblast cells has high potential for providing a microcarrier culture system for the mass production of human IFN- $\beta$.
\end{abstract}

Human interferons (HuIFNs) are now prepared on a large scale for clinical use. The type of IFN most widely used in initial clinical trials is the leucocyte IFN $(\mathrm{HuIFN}-a)$ produced by peripheral blood leucocytes that have been stimulated with Sendai virus (16). It is difficult, however, to obtain a large supply of fresh human leucocytes in ordinary laboratories. In contrast, human fibroblast cells can be readily prepared from neonatal foreskins or embryonic tissues, and they appear to be suitable cells to use for preparing HuIFN for clinical applications. The non-malignant properties of such fibroblast strains can be easily checked by monitoring their finite life span, karyotype, tumorgenicity, etc.

We therefore decided to examine the conditions of IFN production with human fibroblast cells. Several hundred strains of human fibroblast cells have been established in our laboratory from various kinds of tissues that include neonatal foreskins, embryonic tissues and amnions. Fortunately, we were able to obtain several suitable strains for HuIFN- $\beta$ production by our method of cell selection (10).

It has been difficult, however, to obtain a large quantity of HuIFN- $\beta$ because of

* Present address: Biomaterials Research Institute Co., Ltd. 1 Taya-cho Sakae-ku, Yokohama 244, Japan

Abbreviations used: HC, hydrocortisone; PNCS, precolostrum newborn calf serum; HuIFN, human interferon; FCS, fetal calf serum. 
the impediment of cultivating fibroblast cells on a large scale owing to their anchorage dependency. Although several types of apparatus have been developed for large scale monolayer culture, most seem to be impractical. Recently, a microcarrier culture system has been developed (17) that appears to be serviceable for the large scale cultivation of anchorage-dependent cells $(12,13)$. With this microcarrier system, Giard et al. $(7,8)$ and Clark et al. (1) reported IFN- $\beta$ production by human fibroblast cells, and demonstrated the potential of this culture system for the economical mass production of HuIFN- $\beta$.

No large scale production of IFN- $\beta$ by fibroblast cells in a microcarrier culture system has yet been reported. The major reason is that it is difficult to propagate fibroblast cells serially on microcarriers.

We have described our investigation of the culture conditions necessary for the serial propagation of human fibroblast cells, an important factor for large scale cultivation, and IFN production by human fibroblast cells. The type of serum obtained at a specific time during development appears to be highly important for cell growth and IFN production in our microcarrier culture system, but it is less critical in conventional monolayer culture.

\section{MATERIALS AND METHODS}

Cells. Human diploid fibroblast strains, designated FC1 and FC2 cells, were used in experiments on cell growth and IFN production. These cell strains were derived from human neonatal foreskins that had been supplied by Dr. R.E. Gills of the Providence Hospital, Anchorage, Alaska. The in vitro life span of these cell strains were approximately 60 population doubling levels (PDL) under conventional monolayer culture conditions. Karyotypic analysis of these strains showed that $95 \pm 3 \%$ of the cells had normal diploid chromosomes throughout their life spans. FC1 and FC2 cells differed in their sensitivity to the glucocorticoid-promoting effect of cell growth.

FL cells maintained in a spinner culture with Eagle's MEM (No. 4, Nissui Seiyaku Co., Tokyo) supplemented with $5 \%$ precolostrum newborn calf serum (PNCS, Mitsubishi Kasei Institute for Life Science, Machida) were the assay cells used for IFN titration.

Microcarriers. Cytodex 1 and 3 (Pharmacia Fine Chemical AB, Uppsala) at $3 \mathrm{mg} / \mathrm{ml}$ were the microcarriers used in our routine experiments. Cytodex 1 is made of cross-linked dextran and has a positive charge (N,N-diethylaminoethyl, DEAE). Cytodex 3 is a crosslinked dextran microsphere covered with a layer of denatured collagen. All the data given here were obtained from the experiments with Cytodex 1.

Cell culture. Stock cultures of human fibroblast strains were maintained as conventional monolayers in Roux bottles or in microcarrier spinner bottles. In the small scale, routine experiments, plastic tissue culture flasks (Corning 25100, surface area $25 \mathrm{~cm}^{2}$, Iwaki Glass, Tokyo) were used to contain the monolayer cultures, and 500-ml glass spinner bottles (Wilbur Scientific Inc., Boston), $200 \mathrm{ml}$ of stock culture per bottle were used for the microcarrier cultures.

Experiments usually were performed at a passage level of 20-45 PDL of cells but in some cases older cells (up to 65 PDL) were used. The medium used for stock cultures was Eagle's MEM supplemented with $5 \%$ PNCS. Various bovine sera from developing animals were used for serial long term cultivation of the diploid fibroblast strains in the microcarrier culture, and the culture medium was replenished every two or three days.

IFN production. The super-induction procedure for IFN- $\beta$ production reported by 
Vilcek and Havell (18) was modified slightly as follows. Confluent monolayer cultures on microcarriers were primed for $20 \mathrm{~h}$ at $37^{\circ} \mathrm{C}$ with 100 international reference units (IU)/ml of IFN- $\beta$ in Eagle's MEM containing $0.2 \%$ carboxymethyl cellulose (Daicel Chemical Industries Ltd., Osaka), then treated at the same temperature for $4 \mathrm{~h}$ with $50 \mu \mathrm{g} / \mathrm{ml}$ of poly I : poly C (Yamasa Shoyu Co. Ltd., Choshi) together with $10 \mu \mathrm{g} / \mathrm{ml}$ of cycloheximide (Wako Pure Chemical Ind. Ltd., Osaka). After $4 \mu \mathrm{g} / \mathrm{ml}$ of Actinomycin D (Makor Chemicals Ltd., Jerusalem) had been added, the cultures were incubated for $1 \mathrm{~h}$ more, then washed twice with Eagle's MEM containing $0.05 \%$ methylcellulose (Nakarai Chemicals Ltd., Kyoto), after which they were incubated in the same medium at $37^{\circ} \mathrm{C}$. The culture supernatant harvested at $43 \mathrm{~h}$ provided the crude HuIFN- $\beta$ preparation.

IFN assay. IFN titer was determined by the cytopathic effect inhibition method that used FL cells and vesicular stmatitis virus (VSV) in 96-well microtiter plates (Corning Glass Works, New York) (11). The IFN titer was expressed in terms of the international reference HuIFN- $\beta$ (G-02-902-527) obtained from the Research Resources Branch, NIH, Bethesda, Md.

Other tests. Cells in the microcarrier cultures were counted by the nuclei-counting method of Sanford et al. (15). The cells in Roux bottles and plastic flasks were dispersed with $0.25 \%$ trypsin, then counted with a hemocytometer.

Karyotypic analysis of the cells was done by the method of Furuyama and Chiyo (6).

The hydrocortisone contents of the various bovine sera used were analyzed by the solid phase radioimmunoassay (19). Hydrocortisone, dexamethasone and prednisolone were purchased from Wako Pure Chemical Ind. (Osaka).

\section{RESULTS}

Serial propagation of cells and serum species. FC2 cells can grow serially in medium supplemented with $5 \%$ PNCS under microcarrier culture conditions (Fig. 1). This figure shows that the growth rate and cell density of young cells (less than 50 PDL) were high but decreased gradually after 50 PDL. The cells could not be subcultured on microcarriers more than twice in medium supplemented with $5 \%$ FCS (Fig. 3)

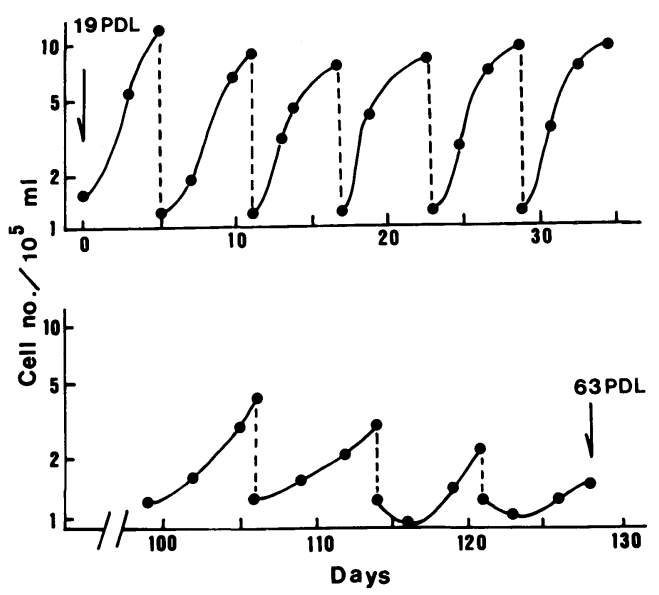

Fig. 1. Serial propagation of FC2 cells in microcarrier culture. FC2 cells were cultured in Eagle's MEM supplemented with $5 \%$ of PNCS then subcultured serially. The culture medium was replenished every two days. 


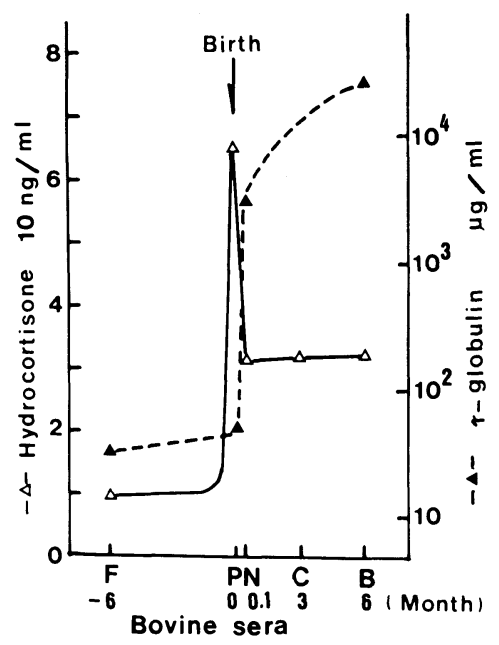

Fig. 2. Analyses of hydrocortisone and $\gamma$-globulin contents of various aged bovine sera. F. Fetal calf serum; P. Precolostrum newborn calf serum; N. Newborn calf serum; C. Calf serum; B. Bovine (adult) serum.

even though FCS is the best supplement for the serial growth of human fibroblast cells in conventional monolayer cultures.

Sera from both adult and newborn cows also did not support the serial propagation of human fibroblast cells. The PNCS that had been specially collected from a newborn calf who had not yet sucked was the only serum species which supported the serial growth of these fibroblast cells in microcarrier cultures.

Effect of glucocorticoid hormones on the growth of human fibroblast cells. To clarify the differences between PNCS and other bovine sera, we analyzed the concentrations of such proteinaceous components and physiologically active substances as albumin, globulin, transferrin, insulin, prostaglandines, ACTH, $\alpha$-fetoprotein and HC. The most distinctive characteristic of PNCS was its high HC content. The content of $\mathrm{HC}$ together with that of globulin in various bovine sera is shown in Fig. 2. The amount of $\mathrm{HC}$ is low in FCS, reaches a maximum in PNCS and decreases again in newborn calf serum (NCS). The HC content in PNCS is at least ten fold that in FCS.

Based on our analysis of the $\mathrm{HC}$ contents of various sera, we investigated the effect of $\mathrm{HC}$ on the cell growth of human fibroblast cells on microcarriers. FC2 cells could not be subcultured in Eagle's MEM supplemented with FCS alone, but could be propagated by adding HC, together with FCS, to the culture medium (Fig. 3). This figure also shows that the growth rate and maximum cell density in culture medium supplemented with FCS and HC were better than with PNCS.

The effect of $\mathrm{HC}$ on the growth of $\mathrm{FCl}$ cells near senescence is shown in Fig. 4. Although $\mathrm{FCl}$ cells are less sensitive to the growth-promoting activity of $\mathrm{HC}$ than are FC2 cells, $\mathrm{HC}$ had marked stimulatory effects on the growth rate and life span of cells cultured on microcarriers. Senescent cells could grow when HC was added to the culture, but the growth rate was less than that of younger cells.

In the presence of $\mathrm{HC}$, cell proliferation was estimated as being about one hundred times that in the absence of HC. The effects of other glucocorticoid hormones, 


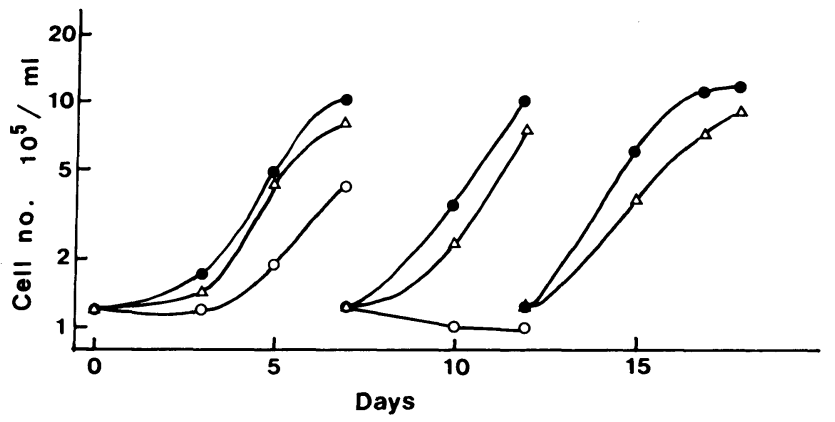

Fig. 3. Effect of hydrocortisone on the growth of FC2 cells in microcarrier culture. FC2 cells proliferated on microcarriers in Eagle's MEM supplemented with $5 \%$ FCS in the presence, or absence, of $\mathrm{HC}$. The control culture was grown in the same medium supplemented with $5 \%$ PNCS. Symbols: - FCS $(5 \%)+\mathrm{HC}(1 \mu \mathrm{M})$; O FCS $(5 \%) ; \triangle \operatorname{PNCS}(5 \%)$

dexamethasone and prednisolone, on cell growth were similar to the effect of $\mathrm{HC}$ (data not shown).

Differential effect of $\mathrm{HC}$ on the growth of monolayer- and microcarrier-cultured cells. HC depressed cell growth in conventional monolayer cultures, whereas it enhanced cell proliferation on microcarriers. The dose effect of $\mathrm{HC}$ on the growth of $\mathrm{FCl}$ cells in monolayer and microcarrier cultures is shown in Fig. 5, in which there is an inverse effect of $\mathrm{HC}$ on fibroblast growth in monolayer and microcarrier cultures.

The effect of $\mathrm{HC}$ on the growth of cells when two different substrata, polystyrene and glass, were used also was examined. There was no apparent difference between these substrata and the $\mathrm{HC}$ effect (data not shown). We also found that the effect of $\mathrm{HC}$ on the growth of human fibroblast cells was the same on both types of microcarriers, Cytodex 1 and 3 (data not shown).

Effect of glucocorticoid hormones on the production of human IFN- $\beta$. Enrichment of the culture medium with glucose and amino acids increased the cell density (data

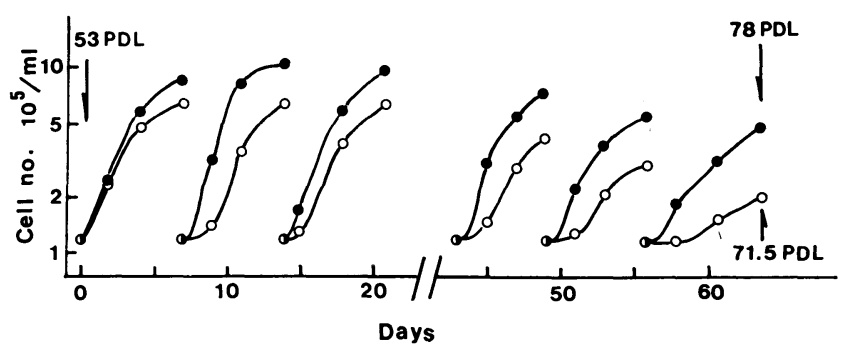

Fig. 4. Effect of hydrocortisone on the growth and life span of FC1 cells near senescence. FC1 cells (53PDL) were cultured serially in Eagle's MEM supplemented with $5 \%$ FCS in the presence (๑), or absence (O), of $1 \mu \mathrm{M}$ HC. Doubling numbers and cell multiplications of the senescent cells:

\begin{tabular}{c|c|c|c}
\hline Medium & Doubling no. & Multiplication & Ratio \\
\hline$\circ$ & 18.5 & $3.7 \times 10^{5}$ & 1 \\
\hline$\bullet$ & 25.0 & $3.4 \times 10^{7}$ & 91 \\
\hline
\end{tabular}




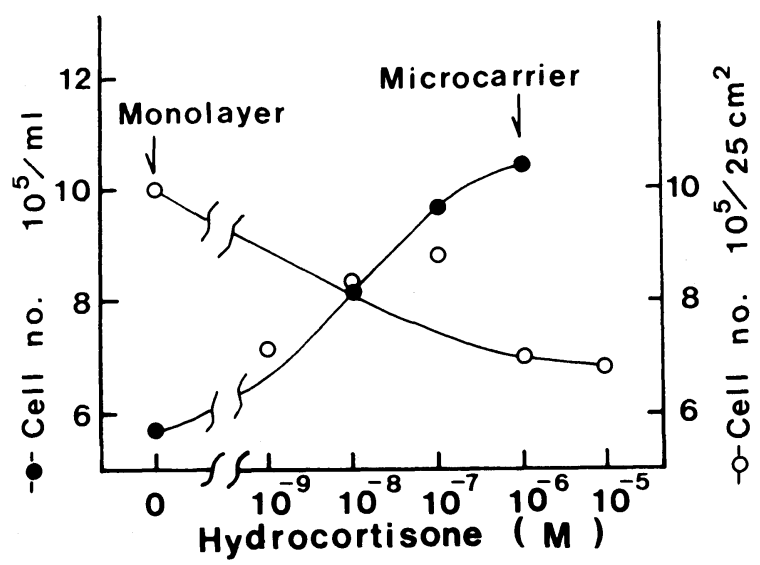

Fig. 5. Effect of hydrocortisone concentrations on the growth of FC1 cells in monolayer and microcarrier cultures. The culture medium was Eagle's MEM supplemented with $5 \%$ FCS and HC at various concentrations. For monolayer culture, $2.0 \times 10^{5}$ cells were seeded in $25-\mathrm{cm}^{2}$ plastic flasks with $10 \mathrm{ml}$ of culture medium, and for microcarrier cultures of $200-\mathrm{ml}$ volume, $2.4 \times 10^{7}$ cells were seeded. Monolayer- and microcarrier-cultured human fibroblast cells were counted seven days after seeding. The cell numbers given are from secondary subcultures because the effect of $\mathrm{HC}$ was not clear in the first subculture.

not shown), but, IFN yields from cells cultured in such enriched medium were generally smaller than those from the control cultures. Cell growth also was promoted by additions of insulin, transferrin and fibronectin to serum-free or low serum media, but the IFN yields were somewhat low (data not shown).

Human fibroblast cells grown on microcarriers in the presence of glucocorticoid hormones maintained their ability to produce IFN- $\beta$ when super-induced with poly I: poly $\mathrm{C}$ and antimetabolites, even in the presence of a low concentration of FCS

TABLE 1. EFFECTS OF HYDROCORTISONE CONCENTRATIONS ON CELL GROWTH AND HUIFN- $\beta$ PRODUCTION BY FC1 CELLS IN MICROCARRIER CULTURE

\begin{tabular}{|c|c|c|c|c|c|c|}
\hline & & \multicolumn{5}{|c|}{ HC concentrations $(\mathrm{M})$} \\
\hline & & 0 & $10^{-8}$ & $10^{-7}$ & $10^{-6}$ & $10^{-5}$ \\
\hline \multirow{4}{*}{ Exp. 1} & IFN (IU/ml) & 6800 & 11000 & 13400 & 12700 & 12000 \\
\hline & Cell no. $\left(\times 10^{5} / \mathrm{ml}\right)$ & 6.8 & 8.1 & 9.8 & 10.5 & 10.0 \\
\hline & IFN (IU/10 cells) & 1000 & 1360 & 1370 & 1210 & 1200 \\
\hline & IFN (IU/ml) & 7200 & 9600 & 16800 & 23000 & 15000 \\
\hline \multirow[t]{3}{*}{ Exp. 2} & Cell no. $\left(\times 10^{5} / \mathrm{ml}\right)$ & 7.0 & 7.9 & 9.8 & 11.0 & 10.5 \\
\hline & IFN (IU/10 cells) & 1030 & 1220 & 1710 & 2090 & 1430 \\
\hline & IFN (IU/ml) & 2000 & ND & 5300 & 9600 & ND \\
\hline \multirow[t]{2}{*}{ Exp. 3} & Cell no. $\left(\times 10^{5} / \mathrm{ml}\right)$ & 3.2 & ND & 5.7 & 6.2 & ND \\
\hline & IFN (IU/10 cells) & 630 & & 930 & 1550 & \\
\hline
\end{tabular}

Cells were cultured in Eagle's MEM containing 2\% (Exp. 3) or 5\% (Exps. 1 and 2) FCS together with $\mathrm{HC}$ at various concentrations. Cells became confluent on the microcarriers seven days after inoculation. These confluent cells were used for the IFN production experiments described in Materials AND Methods. 
TABLE 2. Chromosome Number ANALYSIS OF FC1 AND FC2 CELLS GROWN ON MICROCARRIERS

\begin{tabular}{ccccccccccccc}
\multirow{2}{*}{ Cell } & & & \multicolumn{8}{c}{ Chromosome composition } & Total & Diploidy \\
& & PDL & HC & 42 & 43 & 44 & 45 & 46 & 47 & 92 & Cell no. & $(\%)$ \\
\hline \multirow{5}{*}{ FC1 } & 51 & - & 0 & 0 & 3 & 7 & 189 & 1 & 0 & 200 & 94.5 \\
& 61 & - & 1 & 0 & 1 & 2 & 197 & 1 & 1 & 203 & 97.0 \\
& 52 & + & 0 & 0 & 0 & 6 & 192 & 2 & 0 & 200 & 96.0 \\
& 63 & + & 0 & 0 & 1 & 4 & 201 & 0 & 1 & 207 & 97.6 \\
& 53 & - & 0 & 0 & 0 & 4 & 194 & 2 & 0 & 200 & 97.0 \\
& 63 & - & 0 & 0 & 2 & 7 & 187 & 0 & 4 & 200 & 93.5 \\
FC2 & 57 & + & 0 & 0 & 1 & 10 & 189 & 2 & 0 & 202 & 93.6 \\
& 74 & + & 0 & 0 & 1 & 7 & 187 & 2 & 3 & 200 & 93.5 \\
\hline
\end{tabular}

$(2 \%)$ (Table 1, Exp. 3). Table 1 shows the dose effect of $\mathrm{HC}$ on the production of HuIFN- $\beta$ in $\mathrm{FCl}$ cells grown on microcarriers. The concentration of $\mathrm{HC}$ for maximum enhancement of HuIFN- $\beta$ production was from $10^{-7}$ to $10^{-6} \mathrm{M}$.

Karyotypic analysis. Results of chromosome number analyses of $\mathrm{FCl}$ and $\mathrm{FC} 2$ cells grown on microcarriers in Eagle's MEM with a FCS supplement with, or without, HC are shown in Table 2. Both cell types showed diploidy of more than $93 \%$ regardless of whether $\mathrm{HC}$ was present. Thus, glucocorticoid hormones did not cause chromosomal disorder of our cultured human fibroblast cells.

\section{DISCUSSION}

Recently reports describing the effects of glucocorticoid hormones on cell proliferation in vitro have appeared $(5,9)$. According to those studies, the glucocorticoid effects on cell proliferation vary, some cells are stimulated, some inhibited and some are unaffected by glucocorticoid hormones. The responses have been shown to be dependent, to some extent, on donor species, origin of tissue, stage of ontogeny and cell type $(5,9)$.

In our experiments, growth of human fibroblast cell strains derived from neonatal foreskins was stimulated by $\mathrm{HC}$ in microcarrier cultures, but was suppressed in conventional monolayer cultures. In contrast, these fibroblast cells could not be subcultured serially on microcarriers in $5 \%$ FCS, even though FCS was the best supplement for serial cell growth in monolayer cultures.

These results suggest that differences exist between cells grown on microcarriers and those cultured as monolayers. It may be that these two types of cultured cells differ in the concentration of HC-binding sites per cell because of the difference in the culture methods used. We are now engaged in studies to determine why the effect of $\mathrm{HC}$ on the growth of microcarrier-grown and monolayer-cultured cells differ.

$\mathrm{HC}$ is known to prolong the life span of such human diploid cells as WI-38 and IMR-90 cells derived from fetal lung tissues $(3,14)$, and HC similarly promoted the growth of human fibroblast cell strains obtained in our laboratory and prolonged their life spans in microcarrier cultures. Previously, Cristfalo et al. reported that loss of responsiveness to $\mathrm{HC}$ takes place in aging monolayer cultures because of the 
decrease in the concentration of specific binding sites to HC per cell (4). But, in our strains cell growth was stimulated and the life span prolonged when HC was added to the culture medium of the microcarrier culture, even though cells were senescent (more than 53 PDL) (Fig. 4).

PNCS collected from a newborn calf who had not yet suckled was the only serum species able to support the serial growth of human fibroblast cells in microcarrier culture. PNCS had a content of HC higher than any other bovine sera, which agrees with the results of Comline et al. (2), who described a pronounced rise and turnover of plasma cortisol in fetal lamb just before normal parturition. Therefore, we believe that the major difference between PNCS and other sera which aid serial cell growth in microcarrier cultures is the content of HC. Actually, human fibroblast cells could proliferate serially on microcarriers when $\mathrm{HC}$ was added to culture medium supplemented with FCS that already contained a very low HC content.

The concentration of $\mathrm{HC}$ for maximum growth enhancement in microcarrier culture is from $10^{-7}$ to $10^{-6} \mathrm{M}$ (Fig. 5). As PNCS contains about $2 \times 10^{-7} \mathrm{M}$ of HC, we consider that the ability of PNCS to support the serial propagation of fibroblast cells on microcarriers is attributable to its $\mathrm{HC}$ content.

\section{REFERENCES}

1. Clark, J.M. and M.D. Hirtenstein. High yield culture of human fibroblasts on microcarriers: A first step in production of fibroblast derived interferon. J. Interferon Res. 1, 391-400, 1981

2. Comline, P.S., P.W. Nathanielsz, R.B. Paisey and M. Silver. Cortisol turnover in the sheep foetus immediately prior to parturition. J. Physiol., London, 210, 141-142, 1970

3. Cristfalo, V.J. In; Aging in Cell Tissue Culture. ed. Holeckova, E. and V.J. Cristfalo. pp. 83-119, Plenum Press, New York, 1970

4. Cristfalo, V.J. and B.A. Rosner. Modulation of cell proliferation and senescence of WI-38 cells by hydrocortisone. Fed. Proc. 38, 1851-1856, 1979

5. Cristfalo, V.J. and B.A. Rosner. Glucocorticoid modulation of cell proliferation. In; Tissue Growth Factors, Handbook of Experimental Pharmacology, ed. Baserga, R., SpringerVerlag, Berlin, Heidelberg, New York, 1981

6. Furuyama, J. and T. ChiYo. Methods for chromosome analysis. Clinical Laboratory, 7, 281288, 1977 (in Japanese)

7. Giard, D.J., D.H. Loeb, W.G. Thilly, D.I.C. WANG and D.W. Levine. Human interferon production with diploid fibroblast cells grown on microcarriers. Biotechnol. Bioeng., 21, 433442, 1979

8. GIARD, D.J. and R.J. FleISCHAKER. Examination of parameters affecting human interferon production with microcarrier-grown fibroblast cells. Antimicrobial Agents and Chemotherapy, 18, 130-136, 1980

9. Grove, G.L., B.A. Houghton, J.W., E.D. Kress and V.J. CristFalo. Hydrocortisone effects on cell proliferation: specificity of response among various cell types. Cell Biol. Internat. Rep. 1, 147-155, 1977

10. Kobayashi, S., M. Iizuka, M. Hara, H. Ozawa, T. Nagashima and J. Suzuki. Preparation of human fibroblast interferon for clinical trials. In; The Clinical Potential of Interferons. ed. Kono, R. and J. Vilcek. Tokyo, University of Tokyo Press, pp. 57-68, 1982

11. Kobayashi, S., Y. Togami and K. Hosoi. Interferon. In; Methods for Immuno-biochemical Research, ed. Osawa, T., Tokyo Kagaku Dojin, Tokyo, pp. 245-262, 1985 (in Japanese)

12. Levine, D.W., J.S. Wong, D.I.C. WAng and W.G. Thilly. Microcarrier cell culture: New methods for research-scale application. Somatic Cell Genet., 3, 149-155, 1977 
13. Levine, D.W., D.I.C. WANG and G.W. ThILlY. Optimization of growth surface parameter in microcarrier cell culture. Biotechnol. Bioeng., 2, 821-845, 1979

14. Nichols, W.W., D.G. MurPhy, L.H. Toji, A.E. Green and S.A. Dwight. Characterization of a new human diploid cell strain, IMR-90. Science, 196, 60-63, 1977

15. Sanford, K.K., W.R. Earle, V.J. Evans, K.H. Waltz and J.E. Shannon. Measurement of proliferation in tissue culture by enumeration of cell nuclei. J. Natl. Cancer I. 11, 773-795, 1951

16. Strander, H. and K. Cantell. Studies on antiviral and antitumor effect of human leucocyte interferon in vitro and in vivo. In; Tissue Culture Association, ed. Waymouth, C., Rockville, Md., pp. 49-56, 1974

17. VAN WeZeL, A.L. Growth of cell strains and primary cells on microcarriers in homogeneous culture. Nature, 216, 64-65, 1967

18. VILCEK, J. and A.H. EDWARD. Stabilization of interferon messenger RNA activity by treatment of cells with metabolic inhibitors and lowering of the incubation temperature. Proc. Natl. Acad. Sci. U.S.A., 70, 3909, 1973

19. WakAbayashi, K. and M. Hattori. Radio immunoassay. In; Analytical Methods for Hormones. ed. Imura, H. and K. Miyai, Kodansha, Tokyo, pp. 97-127, 1984 (in Japanese)

(Received for publication, July 23, 1987) 